\title{
Highly effective and safe polymeric inhibitors of herpes simplex virus in vitro and in vivo
}

\author{
Magdalena Pachota ${ }^{a, b}$, Katarzyna Klysik-Trzciańska ${ }^{c}$, Aleksandra Synowiec ${ }^{b}$, Shotaro \\ Yukioka $^{d}$, Shin-Ichi Yusa ${ }^{d}$, Mateusz Zajac c , Barbara Zawilinska ${ }^{e}$, Tomasz Dzieciątkowskif, \\ Krzysztof Szczubialka ${ }^{c}$, Krzysztof Pyrc ${ }^{a}$ *, Maria Nowakowska ${ }^{c, *}$
}

${ }^{a}$ Virogenetics Laboratory of Virology, Malopolska Centre of Biotechnology, Jagiellonian University, 30-387 Krakow, Poland.

${ }^{\mathrm{b}}$ Microbiology Department, Faculty of Biochemistry, Biophysics and Biotechnology, Jagiellonian University, 30-387 Krakow, Poland.

${ }^{\mathrm{c}}$ Department of Physical Chemistry, Faculty of Chemistry, Jagiellonian University, 30-387 Krakow , Poland

${ }^{\mathrm{d}}$ Department of Applied Chemistry, Graduate School of Engineering, University of Hyogo, Himeji, Hyogo, 671-2280 Japan

${ }^{\mathrm{e}}$ Department of Virology, Chair of Microbiology, Faculty of Medicine, Jagiellonian University Medical College, 31-121 Krakow, Poland

${ }^{\mathrm{f}}$ Chair and Department of Medical Microbiology, Warsaw Medical University, 02-004

Warsaw, Poland

\section{Corresponding Authors}

*Maria Nowakowska, e-mail: nowakows@ chemia. uj. edu.pl

*Krzysztof Pyrć, e-mail: k.a.pyrc@uj.edu.pl 


\section{Synthesis of PEG $_{45}-b$-PMAPTAC 9}

PEG$_{45}$-CPD (1.01 g, $0.444 \mathrm{mmol}, M_{\mathrm{w}}=2277$ ), MAPTAC (1.08 g, $\left.4.89 \mathrm{mmol}\right)$ and 4,4'-azobis(4cyanopentanoic acid) (V-501, $99.3 \mathrm{mg}, 0.354 \mathrm{mmol})$ were dissolved in water $(4.9 \mathrm{ml})$. The aqueous solution was degassed by purging with argon for $30 \mathrm{~min}$. Block copolymerization was carried out at $70^{\circ} \mathrm{C}$ for $3 \mathrm{~h}$. After the reaction, the conversion of MAPTAC estimated from ${ }^{1} \mathrm{H}-\mathrm{NMR}$ was $98.4 \%$. The diblock copolymer was purified by dialysis against deionized water for one day. $\mathrm{PEG}_{45}-b$ PMAPTAC $_{9}$ was recovered by a freeze-drying technique $(1.21 \mathrm{~g}$, yield of purified product accounted for $58.5 \%)$. The number-average molecular weight $\left(M_{\mathrm{n}}\right)$, DP estimated from ${ }^{1} \mathrm{H}$ NMR, and molecular weight distribution $\left(M_{\mathrm{w}} / M_{\mathrm{n}}\right)$ estimated from gel-permeation chromatography (GPC), are given in Table $\mathbf{S 1}$ below.

Table S1. The characteristics of the PEG PM-PMAPTAC $_{\mathrm{y}}$ block copolymers

\begin{tabular}{|l|c|c|c|}
\hline & $M_{n}(N M R)$ & $M_{n}(G P C)$ & $\frac{M_{n}}{M_{w}}$ \\
\hline PEG $_{10} b-$ PMAPTAC $_{5}$ & 1500 & 7400 & 1.46 \\
\hline PEG $_{10} b-$ PMAPTAC $_{19}$ & 4600 & 11000 & 1.28 \\
\hline PEG $_{45} b-$ PMAPTAC $_{5}$ & 3400 & 8150 & 1.30 \\
\hline PEG $_{45} b-$ PMAPTAC $_{9}$ & 4300 & 9800 & 1.22 \\
\hline PEG $_{45} b-$ PMAPTAC $_{22}$ & 7120 & 11300 & 1.24 \\
\hline PEG $_{45} b-$ PMAPTAC $_{40}$ & 11100 & 16000 & 1.14 \\
\hline PEG $_{45} b-$ PMAPTAC $_{51}$ & 13500 & 16600 & 1.14 \\
\hline PEG $_{45} b-$ PMAPTAC $_{52}$ & 13830 & 13800 & 1.16 \\
\hline PEG $_{45} b-$ PMAPTAC $_{58}$ & 15000 & 18200 & 1.16 \\
\hline PEG $_{45} b-$ PMAPTAC $_{74}$ & 18700 & 13700 & 1.16 \\
\hline PEG $_{45} b-$ PMAPTAC $_{87}$ & 21400 & 20800 & \\
\hline PEG $_{45} b-$ PMAPTAC $_{102}$ & 24700 & & \\
\hline
\end{tabular}


Table S2. Hydrodynamic diameters, degree of dispersion and zeta potentials of PEG $-b$ PMAPTAC $\mathrm{C}_{\mathrm{y}}$ in aqueous solutions

\begin{tabular}{|c|c|c|c|c|c|c|}
\hline \multirow[t]{2}{*}{ Polymer } & \multicolumn{2}{|c|}{$\begin{array}{c}\text { Hydrodynamic diameter } \\
{[\mathrm{nm}]}\end{array}$} & \multicolumn{2}{|c|}{ Dispersion (PDI) } & \multicolumn{2}{|c|}{ Zeta potential $[\mathrm{mV}]$} \\
\hline & $0.1 \mathrm{~g} / \mathrm{l}$ & $1 \mathrm{~g} / \mathrm{l}$ & $0.1 \mathrm{~g} / \mathrm{l}$ & $1 \mathrm{~g} / \mathrm{l}$ & $0.1 \mathrm{~g} / \mathrm{l}$ & $1 \mathrm{~g} / \mathrm{l}$ \\
\hline PEG $_{45} b$-PMAPTAC $C_{22}$ & $149.6 \pm 4.9$ & $29.4 \pm 4.9$ & $0.332 \pm 0.002$ & $0.995 \pm 0.011$ & $7.5 \pm 0.8$ & $25.2 \pm 1.8$ \\
\hline PEG45- $b$-PMAPTAC 40 & $121.0 \pm 1.8$ & $83.4 \pm 5.2$ & $0.439 \pm 0.023$ & $0.340 \pm 0.114$ & $18.8 \pm 2.4$ & $17.0 \pm 7.9$ \\
\hline PEG $_{45} b$-PMAPTAC 51 & $112.0 \pm 10.4$ & $58.9 \pm 0.3$ & $0.546 \pm 0.010$ & $0.507 \pm 0.042$ & $23.8 \pm 1.0$ & $27.5 \pm 1.3$ \\
\hline PEG $_{45-b \text {-PMAPTAC }} 8$ & $232.2 \pm 17.8$ & $63.9 \pm 26.9$ & $0.728 \pm 0.243$ & $0.646 \pm 0.245$ & $16.1 \pm 4.6$ & $13.8 \pm 2.1$ \\
\hline PEG $_{45}-b$-PMAPTAC 74 & $217.7 \pm 30.8$ & $71.7 \pm 1.8$ & $0.702 \pm 0.220$ & $0.405 \pm 0.085$ & $21.1 \pm 1.9$ & $30.8 \pm 2.1$ \\
\hline PEG $_{45}-b$-PMAPTAC 102 & $261.0 \pm 124.4$ & $12.2 \pm 0.5$ & $0.414 \pm 0.086$ & $0.370 \pm 0.041$ & $22.5 \pm 0.5$ & $20.0 \pm 5.9$ \\
\hline
\end{tabular}

Table S3. Hydrodynamic diameters, degree of dispersion and zeta potentials of PEG $45-b$-PMAPTAC 52 in PBS buffer and salt solutions

\begin{tabular}{|c|c|c|c|c|}
\hline \multicolumn{2}{|c|}{$\begin{array}{c}\text { Concentration of } \text { PEG }_{45}-b \text {-PMAPTAC } \\
{[\mathrm{g} / \mathrm{l}]}\end{array}$} & \multirow{2}{*}{$\begin{array}{c}\begin{array}{c}\text { Hydrodynamic } \\
\text { diameter [nm] }\end{array} \\
140.6 \pm 18.3\end{array}$} & \multirow{2}{*}{$\begin{array}{c}\begin{array}{c}\text { Dispersion } \\
\text { (PDI) }\end{array} \\
0.557 \pm 0.086\end{array}$} & \multirow{2}{*}{$\begin{array}{c}\text { Zeta potential } \\
{[\mathbf{m V}]}\end{array}$} \\
\hline \multirow{5}{*}{$0.001 \mathrm{M} \mathrm{NaCl}$} & 0.05 & & & \\
\hline & 0.10 & $135.2 \pm 10.6$ & $0.549 \pm 0.052$ & $25.9 \pm 2.6$ \\
\hline & 0.25 & $195.6 \pm 23.7$ & $0.893 \pm 0.075$ & $27.8 \pm 3.3$ \\
\hline & 0.50 & $197.1 \pm 9.4$ & $0.364 \pm 0.027$ & $28.7 \pm 1.1$ \\
\hline & 1.00 & $243.1 \pm 15.4$ & $0.666 \pm 0.124$ & $9.49 \pm 0.9$ \\
\hline \multirow{5}{*}{ PBS } & 0.05 & $171.8 \pm 103.4$ & $0.822 \pm 0.275$ & $9.07 \pm 6.2$ \\
\hline & 0.10 & $854.1 \pm 107.0$ & $0.657 \pm 0.118$ & $8.32 \pm 0.8$ \\
\hline & 0.25 & $899.3 \pm 133.1$ & $0.576 \pm 0.034$ & $11.7 \pm 0.6$ \\
\hline & 0.50 & $949.9 \pm 78.9$ & $0.544 \pm 0.054$ & $13.6 \pm 0.6$ \\
\hline & 1.00 & $525.0 \pm 33.4$ & $0.877 \pm 0.214$ & $7.03 \pm 5.3$ \\
\hline
\end{tabular}




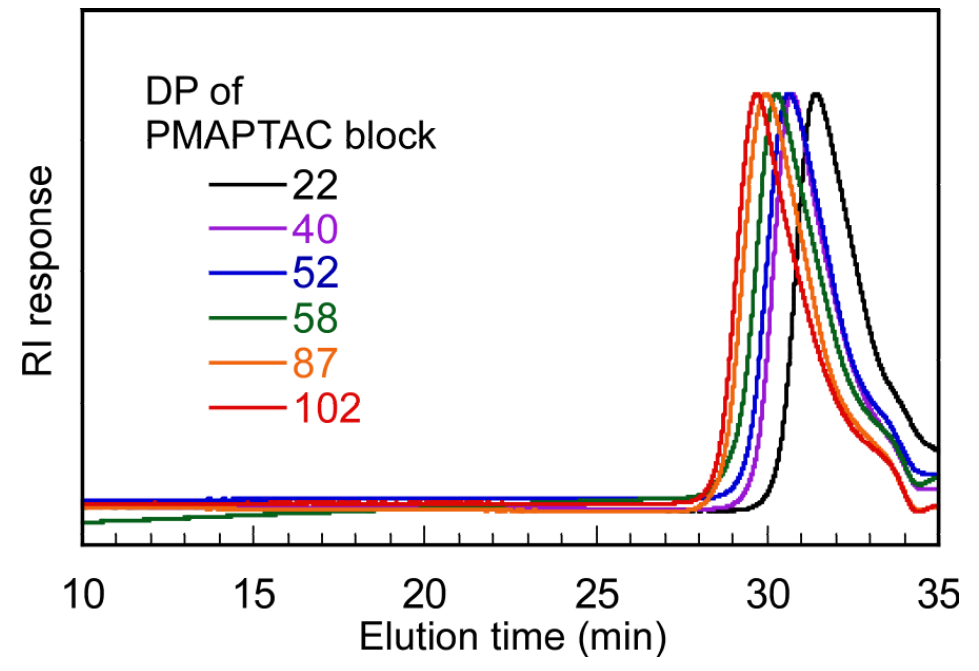

Figure S1. Examples of GPC elution curves of PEG45-b-PMAPTAC $C_{x}(x=22,40,52,58$, 87, and 102) obtained using acetic acid (0.5 M) solution containing sodium sulfate (0.3 M) as an eluent.

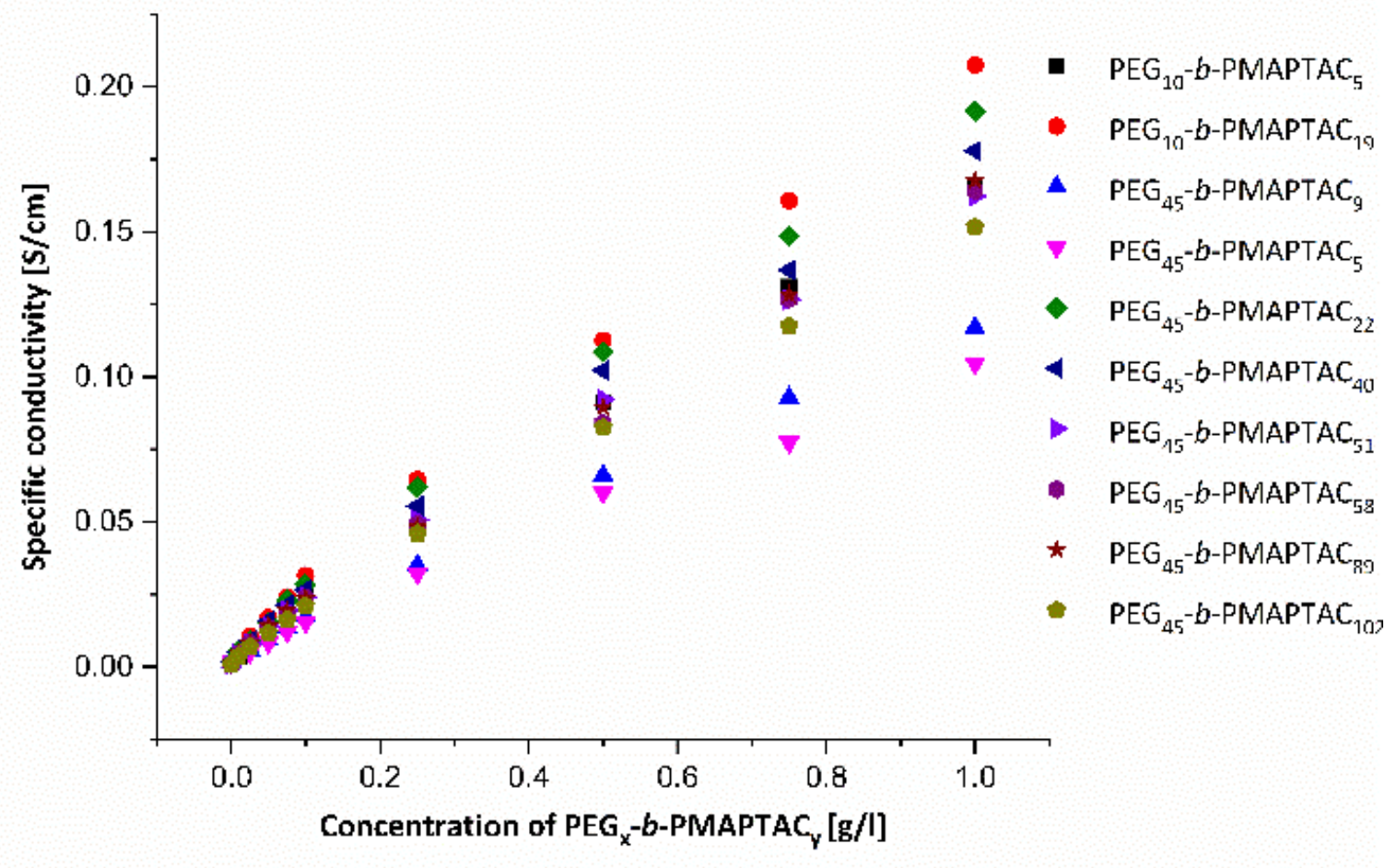

Figure S2. Specific conductivity of the aqueous solutions of the polymers on their concentration. 


\section{Supplementary Materials and Methods \\ Reagents for polymer synthesis}

The chain transfer agent, 4-cyanopentanoic acid 200 dithiobenzoate (CPD) was synthesized according to the method reported by McCormick et al. 1. 3-(Methacrylamido)propyl trimethylammonium chloride (MAPTAC, 95\%, Wako Pure Chemical), 4,4'-azobis (4cyanopentanoic acid) (V-501, 98\%, Wako Pure Chemical) and other reagents were used as received. Water was purified using a Millipore Milli-Q system. PEG $45-C T A$ (PEG $45-C P D$, number-average molecular weight $\left.\left(M_{\mathrm{n}}\right)=2277\right)$ and $\mathrm{PEG}_{10}-\mathrm{CTA}\left(\mathrm{PEG}_{10}-\mathrm{CPD}, M_{\mathrm{n}}=750\right)$ were prepared using a previously reported method ${ }^{2,3}$. Other reagents were used as received.

\section{Cytotoxicity assay}

XTT Cell Viability Assay Kit (Biological Industries) was used to evaluate the cytotoxicity of tested compounds. Vero E6 cells were seeded in 96-well plates and cultured for $24-48 \mathrm{~h}$ until they reached full confluence. Subsequently, the medium was removed and fresh medium containing certain concentrations of tested polymers was applied. Cells were cultured for $48 \mathrm{~h}$ in standard conditions. On the day of the assay, the medium was discarded, and fresh medium supplemented with $25 \mu \mathrm{l}$ of activated XTT reagent was added per well. After $2 \mathrm{~h}$ of incubation at $37^{\circ} \mathrm{C}$, the supernatants were transferred onto the fresh 96-well plate and absorbance was measured at $\lambda=480 \mathrm{~nm}$ (Infinite M200 PRO, Tecan). The results were normalized to untreated cells (100\% viability).

\section{Functional assays}

A set of functional assays was developed to determine the mechanism of antiviral activity of the tested polymers. The assays are briefly described below.

\section{Assay I. Inactivation of virions.}

Aliquots of virus stock were incubated with the polymer at $10 \mu \mathrm{g} / \mathrm{ml}$ for $1 \mathrm{~h}$ at $22^{\circ} \mathrm{C}$ under constant mixing. Subsequently, the samples were diluted to reduce the polymer concentration below its active range $(0.1 \mu \mathrm{g} / \mathrm{ml})$. Negative control samples were prepared in the same manner using PBS instead of polymer solution. Viral yields were assessed using plaque assay. This test allows to determine if the polymer acts directly on the viral particles, inactivating them.

\section{Assay II. Cell protection.}


Monolayers of Vero E6 cells in 96 well plates were incubated with the polymer for $1 \mathrm{~h}$ at $37^{\circ} \mathrm{C}$. Subsequently, the supernatants were removed, cells were washed thrice with PBS and infected with the virus at $\mathrm{TCID}_{50}=400 / \mathrm{ml}$ or inoculated with mock. Following $2 \mathrm{~h}$ incubation at $37^{\circ} \mathrm{C}$, supernatants were discarded, cells were washed thrice with PBS to remove unbound virions and fresh medium was applied. Samples of culture supernatants were collected and analyzed 2 days p.i. In this assay cells were pre-treated with the polymers, which were not present in the media during the infection. For this reason, the inhibition should be observed only if the polymer interacts with the cell, making it non-permissive to the infection.

\section{Assay III. Virus attachment.}

Monolayers of Vero E6 cells in 96 well plates were pre-cooled on ice, overlaid with ice-cold suspension of the virus $\left(\mathrm{TCID}_{50}=400 / \mathrm{ml}\right)$ or mock and tested polymer in culture medium. Samples were incubated at $4^{\circ} \mathrm{C}$ for $1 \mathrm{~h}$. Subsequently, the cells were washed thrice with ice-cold PBS to remove the residual virions and polymers and fresh cell culture medium was applied. Samples of culture supernatants were collected and analyzed 2 days p.i. In this assay the polymers were present only during the virus attachment to cellular receptors and co-receptors and therefore the observable inhibition should result from blockage of this process.

\section{Assay IV. Inhibition of virus replication, assembly and egress.}

Monolayers of Vero E6 cells in 96 well plates were infected with the virus at TCID $_{50}=400 / \mathrm{ml}$ or inoculated with mock and incubated for $2 \mathrm{~h}$ at $37^{\circ} \mathrm{C}$. Subsequently, cells were washed thrice with PBS to remove unbound virions and fresh media supplemented with polymers or control samples were applied. The cultures were maintained for 2 days and culture supernatants were collected for analysis. As the polymers are not present during early stages of the infection, observable inhibition should result from interference of the polymer with virus replication assembly or egress.

\section{qPCR}

Quantitative real-time PCR was used to determine viral yield in samples. Viral DNA was isolated from cell culture supernatants using Viral DNA/RNA Isolation Kit (A\&A Biotechnology, Poland). The reaction mixture $(10 \mu \mathrm{l})$ consisted of $1 \times$ Kapa Probe Fast qPCR Master Mix, specific probe labeled with 6-carboxyfluorescein (FAM) and Black Hole Quencher 1 (BHQ1) (sequence 5'-FAM CCG CCG AAC TGA GCA GAC ACC CGC GC BHQ1-3', 100 $\mathrm{nM}$ ), and primers (450 nM each, sequences, sense primer 5'-CAT CAC CGA CCC GGA GAG 
GGA C-3', antisense primer 5'-GGG CCA GGC GCT TGT TGG TGT A-3') and $2.5 \mu 1$ of template DNA. The reaction was carried out in CFX96 Touch Real-Time PCR Detection System (Bio-Rad) according to the scheme: $3 \mathrm{~min}$ at $95^{\circ} \mathrm{C}$ followed by 37 cycles of $2 \mathrm{~s}$ at $95^{\circ} \mathrm{C}$ and $20 \mathrm{~s}$ at $60^{\circ} \mathrm{C}$. DNA standards were prepared to quantify the results. A fragment of viral DNA polymerase gene common for HSV-1 and HSV-2 strains was amplified using primers described above and cloned into pTZ57R/T (Thermo Scientific, Poland) plasmid with InsTAclone PCR cloning kit (Thermo Scientific, Poland). The plasmid was propagated in E. coli TOP10 (Life Technologies, Poland) and purified with GeneJET Plasmid Miniprep Kit (Thermo Scientific, Poland). After linearization with KpnI restriction enzyme, DNA concentration was measured and the number of DNA copies per milliliter was calculated. Serial dilutions of the DNA standard were used to generate a standard curve.

\section{Confocal microscopy}

Vero E6 cells were seeded on coverslips in 12-well plates and cultured for 2 days. After that time cells were fixed with $4 \%$ paraformaldehyde in PBS for $20 \mathrm{~min}$. Then, cells were permeabilized with $0.1 \%$ Triton X100 in PBS for 20 min and unspecific binding sites were blocked with 5\% BSA in PBS (overnight at $4^{\circ} \mathrm{C}$ ). For virus visualization cells were stained for $2 \mathrm{~h}$ with primary rabbit anti-HSV VP5 antibody (20-HR50, Fitzgerald Industries, USA) diluted 1:500 in PBS with $0.5 \%$ Tween 20, followed by $1 \mathrm{~h}$ incubation with secondary goat anti-rabbit antibody, conjugated with AlexaFluor 488 (A11001, Invitrogen, Poland) diluted 1:200. For staining of F-actin, AlexaFluor 647-conjugated phalloidin (Invitrogen, Poland) diluted 1:50 was used. Nuclear DNA was counterstained with $0.1 \mu \mathrm{g} / \mathrm{ml}$ 4',6'-diamidino-2-phenylindole (DAPI) (Sigma-Aldrich, Poland). Immunostained cultures on coverslips were mounted on glass slides with ProLong Diamond Antifade Mountant (Thermo Scientific, Poland). Fluorescent images were acquired under a ZEISS LSM 710 (release version 8.1) confocal microscope using with ZEN 2012 SP1 (black edition, version 8.1.0.484) software. Stacks acquisition parameters were as follows: frame size $2048 \times 2048$ pixels, step size $0.15 \mu \mathrm{m}$, pixel size $0.13 \mu \mathrm{m}$. ImageJ FIJI version was used for image processing.

\section{In vivo toxicity}

Toxicity studies were conducted on 6 week old female BALB/c mice purchased from The Center for Experimental Medicine of the Medical University of Bialystok. Mice were housed individually at temperature $22^{\circ} \mathrm{C} \pm 2{ }^{\circ} \mathrm{C}$ with relative humidity of $55 \% \pm 5 \%$ and 12 hour light and dark photoperiodic cycles with 20 air changes per hour. 25 animals were divided into 5 
groups $(n=5)$ receiving polymers at concentrations of 1,5 or $10 \% \mathrm{w} / \mathrm{v}$, saline solution, or no treatment at all (control group). The animals were shaved at the lateral dorsal side, the skin was scratched with a needle and the polymer-containing formulation was applied to the scarified area at a volume of $100 \mu \mathrm{l}$ per mouse. The treatment was then administered every $12 \mathrm{~h}$ for 4 consecutive days. The animals were inspected daily for skin abnormalities, general health and weighed daily for 7 days.

\section{In vivo antiviral activity}

Six-week-old female BALB/c mice were shaved at the lateral dorsal side, the skin was scratched with a needle, and $100 \mu \mathrm{l}$ of the polymer-containing formulation per mouse was applied to the scarified area for $30 \mathrm{~min}$. Subsequently, a patch was soaked with $100 \mu \mathrm{l}$ of HSV-1 suspension at $1 \times 10^{7} \mathrm{PFU}$, supplemented with the polymer or control sample, and placed on the scarified area. After $2 \mathrm{~h}$ the patch was removed, and the formulation was re-applied. The treatment was administered every $12 \mathrm{~h}$ for four consecutive days. Each day mice were scored according to the disease scale ( 0 - no signs; 1 - formation of blisters; 2 - slight ulceration; 3 - large patches of ulceration; 4 - confluent band of ulceration; 5 - hind limb paralysis; 6 - death) and general health scale (0 - good condition, no signs of disease; 1 - apathy, ruffled fur, hunching; 2 weight loss no greater than $20 \%$ of the initial weight; 3 - weight loss greater than $20 \%$ of the initial weight; 4 -agony; 5 - death). All the animals were euthanized and subjected to necropsy at the time when first animals reached level 3 in the general health scale.

\section{Statistical analysis}

All experiments were performed in triplicate and results are presented as mean \pm SEM. Oneway ANOVA with Tukey HSD post-hoc test was used to assess statistical significance of acquired results. When the parametric test assumptions were violated the nonparametric Kruskal-Wallis with Dunn's post-hoc test was used. P values of 0.05 and less were considered significant.

(1) Mitsukami, Y.; Donovan, M. S.; Lowe, A. B.; McCormick, C. L. Macromolecules 2001, 34 (7), 2248-2256.

(2) Shi, L.; Chapman, T. M.; Beckman, E. J. Macromolecules 2003, 36 (7), 2563-2567.

(3) Li, Y.; Lokitz, B. S.; McCormick, C. L. Macromolecules 2006, 39 (1), 81-89. 